\section{BMJ Open} Ophthalmology

\title{
Traumatic hyphaema in children: a retrospective and prospective study of outcomes at an Australian paediatric centre
}

\author{
Michael D Richards, ${ }^{1,2}$ Kate Barnes, ${ }^{1,2}$ Anne-Marie E Yardley, ${ }^{1,2}$ Kate Hanman, ${ }^{1,2}$ \\ Geoffrey C Lam, ${ }^{2,3}$ David A Mackey ${ }^{1,3}$
}

To cite: Richards MD, Barnes K, Yardley A-ME, et al. Traumatic hyphaema in children: a retrospective and prospective study of outcomes at an Australian paediatric centre. BMJ Open Ophthalmology 2019;4:e000215. doi:10.1136/ bmjophth-2018-000215

- Additional material is published online only. To view please visit the journal online (http://dx.doi.org/10.1136/ bmjophth-2018-000215).

Received 29 August 2018 Revised 28 November 2018 Accepted 17 December 2018

\section{Check for updates}

(C) Author(s) (or their employer(s)) 2019. Re-use permitted under CC BY-NC. No commercial re-use. See rights and permissions. Published by BMJ.

${ }^{1}$ Lions Eye Institute, Perth, Western Australia, Australia ${ }^{2}$ Department of Ophthalmology, Perth Children's Hospital, Perth, Western Australia, Australia ${ }^{3}$ Centre for Ophthalmology and Visual Science, University of Western Australia, Perth, Western Australia, Australia

Correspondence to Dr Michael D Richards ; michaelrichards@lei.org.au

\section{ABSTRACT}

Objective This study aims to evaluate the presenting characteristics, management, outcomes and complications for paediatric traumatic hyphaema in Western Australia.

Methods and Analysis A retrospective review of medical records was conducted for consecutive patients $\leq 16$ years of age admitted for traumatic hyphaema to Princess Margaret Hospital for Children (Perth, Australia) between January 2002 and December $2013(n=82)$. From this sample, a cohort whose injury occurred $\geq 5$ years prior attended a prospective ocular examination $(n=16)$. Hospital records were reviewed for patient demographics, injury details, management, visual outcomes and complications. The prospective cohort underwent examination for visual and structural outcomes.

Results Most injuries (72\%) resulted from projectile objects. Angle recession was present in $53 \%$ and was associated with projectiles ( $p=0.002)$. Most eyes $(81 \%)$ achieved a final visual acuity of 0.3 logarithm of the minimum angle of resolution (logMAR) (20/40) or better. Age $\leq 5$ years and posterior segment injury were significant predictors of final visual acuity poorer than $0.3 \log M A R$. At $\geq 5$ years post-trauma, injured eyes had greater intraocular pressure $(I 0 P)(p=0.024)$ and anterior chamber depth (ACD) ( $p=0.022)$ compared with sound eyes. IOP asymmetry was associated with angle recession $(p=0.008)$ and ACD asymmetry $(p=0.012)$.

Conclusion Poorer visual outcomes are associated with younger age at injury and posterior segment injury. Angle recession and ACD asymmetry are associated with IOP asymmetry $5-12$ years after injury.

\section{INTRODUCTION}

Eye injuries in childhood are largely preventable but unfortunately remain common. ${ }^{1}$ According to WHO, at least 55 million people worldwide suffer significant eye trauma each year, and up to half of those eye injuries occur in children. ${ }^{2}$ In Australia, the annual rate of hospitalisation for eye injury is estimated at 77 per 100000 population. ${ }^{3}$ Among children admitted to hospital for serious closed-globe injuries, traumatic hyphaema is the most common diagnosis. ${ }^{4}$ It is estimated that traumatic hyphaema affects 17-20 per

\section{Key messages}

What is already known about this subject?

- Children are disproportionately affected by ocular trauma, and traumatic hyphaema is among the most common paediatric eye injuries requiring hospitalisation.

Despite its relatively high prevalence and potential for lifelong complications, the presentation and outcomes of paediatric traumatic hyphaema have received little research attention.

\section{What are the new findings?}

Angle recession was found in approximately $50 \%$ of children admitted for traumatic hyphaema and was more likely to result from projectile injury.

- Poorer visual outcomes were associated with younger age at injury and more severe injury involving the posterior segment.

- 5-12 years postinjury, traumatised eyes had higher intraocular pressure (IOP) compared with uninjured eyes, and greater IOP asymmetry was associated with angle recession and anterior chamber depth (ACD) asymmetry.

How might these results change the focus of research or clinical practice?

A history of projectile injury may heighten clinicians' suspicion for angle recession, which requires longterm IOP monitoring.

- ACD asymmetry holds promise as a surrogate marker for angle recession, particularly for patients in whom gonioscopy is challenging (eg, children).

100000 children annually, ${ }^{56}$ and it accounts for one-third of all paediatric eye injuries requiring hospitalisation in Australia. ${ }^{4}$

Although paediatric traumatic hyphaema can have a good visual prognosis, ${ }^{7}$ complications including rebleeding, amblyopia, elevated intraocular pressure (IOP) and secondary glaucoma can lead to visual impairment or blindness. ${ }^{5689}$ Despite its relatively high prevalence in childhood and the potential for serious complications, few studies have 
specifically examined paediatric traumatic hyphaema. Furthermore, the existing literature on the topic has limited long-term follow-up, reports few visual outcomes and lacks gonioscopic data on angle recession-a key risk factor for secondary glaucoma. ${ }^{710} 11$

The purpose of the present study is twofold: (1) to provide a retrospective profile of paediatric traumatic hyphaema in an Australian paediatric centre, and (2) to assess long-term outcomes and complications through prospective examination of a paediatric traumatic hyphaema cohort 5-12 years postinjury. These data will help to inform eye injury prevention campaigns and public health policies in Australia and provide an evidential basis for the assessment of long-term risks associated with traumatic hyphaema in children.

\section{MATERIALS AND METHODS}

A retrospective review of medical records was conducted for consecutive patients with traumatic hyphaema admitted to the emergency department or inpatient unit at Princess Margaret Hospital for Children (Perth, Western Australia) between January 2002 and December 2013. A computerised search of the hospital admission database for International Classification of Diseases (ICD-10 AM) codes S05.0, S05.1, S05.3, S05.4, S05.8 and S05.9 identified candidate eye injury records during the 12-year period (see online supplementary table 1 for explanation of codes). Inclusion criteria were age $\leq 16$ years and closed-globe injury with traumatic hyphaema. Exclusion criteria were concurrent or past open-globe injuries and absence of hyphaema. Records were manually reviewed to determine the age at injury, sex, residential postcode, circumstances and mechanism of injury, as well as details of clinical presentation, management and follow-up. Initial visual acuity was defined as that documented on presentation to hospital. Final visual acuity was defined as the best-corrected visual acuity documented at the last follow-up visit.

Ocular injuries associated with traumatic hyphaema were classified anatomically as 'Zone 1' (injury to the ocular surface), 'Zone 2' (internal injury to the anterior segment including traumatic mydriasis and iridodialysis) or 'Zone 3' (internal injury to the posterior segment including vitreous haemorrhage, commotio retinae and choroidal rupture).$^{12}$ Injuries to the eyelids, orbital and periorbital tissues were classified as 'Adnexal'. Residential postcodes were classified as 'Urban', 'Regional' or 'Remote' according to the Australian Statistical Geography Standard Remoteness Structure. ${ }^{13}$

All patients from the 12-year cohort who sustained their injury in March 2010 or earlier (ie, $\geq 5$ years prior), and for whom contact information was available, were invited for a recall examination between March and June 2015. The examination included distance visual acuity with habitual refractive correction (Early Treatment Diabetic Retinopathy Study chart), tonometry (Icare TA01i, Icare Finland Oy, Helsinki, Finland), autorefraction (ARK-510A, NIDEK, Japan), SITA-Fast 24-4 automated perimetry (Humphrey Field Analyzer, Zeiss/ Humphrey Systems, Dublin, California, USA), ocular biometry (IOL Master V.5, Carl Zeiss Meditec AG, Jena, Germany), optical coherence tomography (OCT) of the peripapillary retinal nerve fibre layer (RNFL) (Spectralis HRA+OCT, Heidelberg Engineering, Heidelberg, Germany) and slit lamp examination with gonioscopy by an ophthalmologist.

All statistical analyses were performed using IBM SPSS Statistics V.22. Relationships between categorical variables were assessed using Fisher's exact test. Relationships between continuous or ordinal variables were assessed using Pearson's or Spearman's rank correlations, as appropriate. Relationships between categorical and continuous or ordinal variables were assessed using analysis of variance (ANOVA) or the Kruskal-Wallis non-parametric test, as appropriate. Risk factors for poor visual outcome were determined by multivariate logistic regression. Multiple comparisons were adjusted by the Bonferroni method as indicated in the text. Statistical significance was defined as $\alpha=0.05$.

\section{RESULTS}

\section{Part 1: retrospective chart review}

Records of 185 patients were identified from a search of relevant ICD-10 AM codes in the hospital admission database. A manual review identified 83 patients with traumatic hyphaema, one of whom was excluded for prior open-globe injury in the eye with a traumatic hyphaema. A total of 82 patients were included in the final analysis.

\section{Patient demographics: age, sex and remoteness}

Patient demographics are summarised in table 1 . The mean \pm SD age at injury was $9.6 \pm 4.1$ years. The mean age at injury did not differ significantly between boys and girls $(9.36 \pm 4.6$ years vs $9.75 \pm 4.0$ years; $\mathrm{t}[80]=-0.326$, $\mathrm{p}=0.746$ ), or between patients from urban, regional and remote areas $(9.3 \pm 4.3$ years vs $11.3 \pm 3.2$ years vs $10.0 \pm 3.8$ years; $F[2,81]=1.069, \mathrm{p}=0.348$, one-way ANOVA, Bonferroni correction).

\begin{tabular}{|c|c|}
\hline Variable & n (\%) \\
\hline \multicolumn{2}{|l|}{ Age at injury, years } \\
\hline 0 to $<6$ & $17(21)$ \\
\hline 6 to $<12$ & $34(42)$ \\
\hline 12 to $<17$ & $31(38)$ \\
\hline \multicolumn{2}{|l|}{ Sex } \\
\hline Male & $64(78)$ \\
\hline Female & $18(22)$ \\
\hline \multicolumn{2}{|c|}{ Remoteness area classification } \\
\hline Major city of Australia & $61(74)$ \\
\hline Regional Australia & $11(13)$ \\
\hline Remote Australia & $10(12)$ \\
\hline
\end{tabular}




\section{Circumstances of injury}

The circumstances of injury in the traumatic hyphaema cohort are summarised in online supplementary table 2. Traumatic hyphaemas were reported to occur during all waking hours, with injuries peaking in the afternoon $(34 \%)$ and evening $(27 \%)$ hours. Home $(34 \%)$ was the most commonly reported place of injury, followed by outdoors $(18 \%)$ and at school or daycare $(13 \%)$. A large minority of injuries were sport-related $(23 \%)$, with tennis $(6 \%)$, football $(5 \%)$ and cricket $(4 \%)$ the most commonly implicated sports.

\section{Mechanisms of injury}

The mechanisms of injury were classified into two groups: projectile and non-projectile (see online supplementary table 3). A projectile mechanism of injury (ie, injury from an airborne object) was identified in $72 \%$ of cases. Small, thrown items such as rocks and nuts $(27 \%)$, sports items such as balls and shuttlecocks (20\%), and missiles from toy weapons $(9 \%)$ were the most commonly implicated projectile objects. A non-projectile mechanism was identified in $27 \%$ of cases. Handheld items such as toys and sticks (11\%), sport items such as cricket bats and hockey sticks $(5 \%)$, and direct contact with body parts $(5 \%)$ were the most commonly implicated non-projectile objects. Airbag deployment in automobile accidents was responsible for $2 \%$ of traumatic hyphaemas.

The proportion of cases with projectile versus non-projectile mechanisms of injury did not differ significantly between urban, regional and remote areas $(\mathrm{p}=0.360$, Fisher's exact test), between children aged $\leq 5$ years, $6-11$ years and $\geq 12$ years $(p=0.472$, Fisher's exact test), or between boys and girls ( $p=0.163$, Fisher's exact test).

\section{Time interval from injury to specialist eye care}

The time interval from injury to assessment by an eye specialist at Princess Margaret Hospital ranged from the same day to 4 days postinjury. The majority (62\%) of children received specialist eye care within 24 hours of injury. However, there was significant variation in the time interval from injury to accessing specialist eye care by residential remoteness $(\mathrm{p}=0.004$, Kruskal-Wallis test) (see table 2). Post-hoc analysis showed that patients from remote areas experienced a significantly longer delay compared with patients from urban or regional areas (remote vs urban, $\mathrm{p}=0.006$; remote vs regional, $\mathrm{p}=0.007$; regional vs urban, $\mathrm{p}>0.99$; Dunn pairwise comparisons).

\begin{tabular}{|c|c|c|c|c|}
\hline \multirow[b]{2}{*}{ Time interval } & \multicolumn{4}{|l|}{ n (\%) } \\
\hline & Urban & Regional & Remote & Total \\
\hline$<24$ hours & $41(67)$ & $9(82)$ & $1(10)$ & $51(62)$ \\
\hline 24 to $<48$ hours & $15(25)$ & $1(9)$ & $8(80)$ & $24(29)$ \\
\hline 2 days or more & $5(8)$ & $1(9)$ & $1(10)$ & $7(9)$ \\
\hline
\end{tabular}

\section{Clinical presentation upon admission}

The initial visual acuity varied widely, with acuity better than 0.30 logarithm of the minimum angle of resolution (logMAR) $(20 / 40)$ in $29 \%$ of cases, 0.30 to $<1.00$ $(20 / 200)$ in $23 \%$ of cases, and $1.00 \log$ MAR or poorer in $33 \%$ of patients. Initial visual acuity was not recorded in $15 \%$ of cases, of which $83 \%$ were age 5 years or under. In addition to a traumatic hyphaema, two-thirds of cases $(66 \%)$ had other associated injuries to the globe or adnexa. One-third (34\%) of cases had associated injuries to the cornea and conjunctiva (ie, zone 1), most commonly corneal abrasion (29\%). One-third (34\%) of cases had associated injuries to the anterior segment (ie, zone 2), most commonly traumatic mydriasis (31\%) and more rarely iridodialysis $(4 \%)$. Slightly fewer than one-third (27\%) had associated injuries to the posterior segment (ie, zone 3 ), including commotio retinae $(21 \%)$, vitreous haemorrhage $(5 \%)$ and more rarely choroidal rupture $(2 \%)$. Twenty-two per cent of cases had associated injuries to the ocular adnexa, including periorbital abrasions and contusions (9\%), lid laceration (7\%) and orbital fracture $(6 \%)$.

\section{Management}

The vast majority $(96 \%)$ of patients with traumatic hyphaema received topical steroids, approximately two-thirds $(68 \%)$ received a topical cycloplegic agent, and approximately a quarter $(28 \%)$ received an aqueous suppressant following injury. Antibiotics were given to $63 \%$ of patients, and antibiotic use was significantly associated with the presence of associated zone 1 ocular surface injuries $(\mathrm{p}<0.001$, Fisher's exact test). Only one patient $(1 \%)$ required surgical washout of the anterior chamber on day 6 postinjury for sustained IOP of $\geq 60 \mathrm{~mm} \mathrm{Hg}$ for 2 days despite maximal medical therapy. An additional nine patients underwent surgery for repair of associated injuries including lid laceration $(7 \%)$, conjunctival laceration $(4 \%)$ and orbital floor fracture $(1 \%)$.

\section{Length of admission and follow-up}

The mean length of admission to hospital was 4.1 (range 0-16) nights. Longer admission was significantly associated with more remote residential postcode classification $\left(\mathrm{R}_{\mathrm{S}}{ }^{2}=0.100, \mathrm{p}=0.004\right)$. Three patients were readmitted on bed-rest for rebleeding in the first week postinjury.

The mean duration of follow-up was 437 (range 2-3294) days. Shorter follow-up was significantly associated with more remote residential postcode classification $\left(\mathrm{R}_{\mathrm{S}}{ }^{2}=0.059, \mathrm{p}=0.029\right)$.

\section{Complications}

The most common ocular complications in the traumatic hyphaema cohort were elevated IOP $(>21 \mathrm{~mm}$ $\mathrm{Hg}$ ) and angle recession. Among the 77 patients for whom tonometry data were available, $37(48 \%)$ had elevated IOP $>21 \mathrm{~mm} \mathrm{Hg}$ at some point during follow-up. Maximal IOP elevation ranged from $22 \mathrm{~mm} \mathrm{Hg}$ to 64 $\mathrm{mm} \mathrm{Hg}$ and occurred between 0 and 30 days from the 
A)

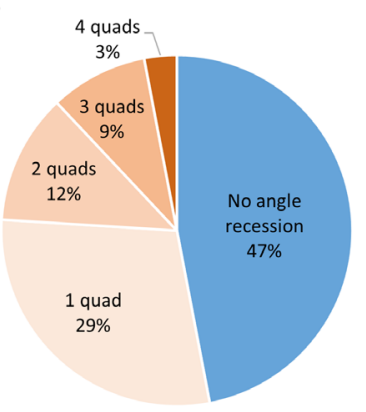

B)

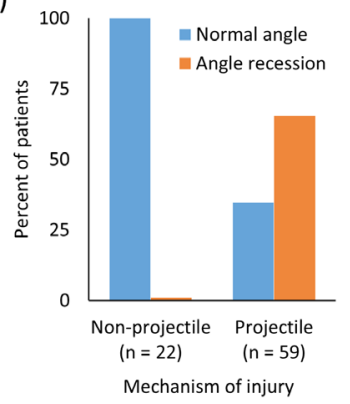

Figure 1 Angle recession on gonioscopy. (A) Number of quadrants of angle recession. 1 quad $=1-3$ clock hours of angle recession; 2 quads $=4-6$ clock hours; 3 quads $=7-9$ clock hours; 4 quads $=10-12$ clock hours. (B) Per cent of patients with and without angle recession by mechanism of injury. Angle recession was significantly associated with a projectile mechanism of injury.

date of injury (see online supplementary figure file 1 ). Among the 34 patients for whom gonioscopy was documented, 18 (53\%) had angle recession (figure 1A). As illustrated in figure $1 \mathrm{~B}$, angle recession was associated with a projectile mechanism of injury ( $\mathrm{p}=0.003$, Fisher's exact test). Other less common anterior segment complications noted on follow-up were mild traumatic cataract managed conservatively in four patients $(5 \%)$, significant traumatic cataract requiring lensectomy in one patient $(1 \%)$, peripheral corneal blood staining in three patients $(4 \%)$ and rebleeding in three patients $(4 \%)$.

Several patients also developed posterior segment sequelae. Two patients (2\%) developed a pigmentary maculopathy, two (2\%) developed retinal tears or detachment, one $(1 \%)$ was diagnosed with a traumatic macular hole and one (1\%) was diagnosed with traumatic optic neuropathy. Two patients suffered more unusual and catastrophic retinal complications: one patient with extensive commotio retinae developed traumatic retinal necrosis, and another with associated choroidal rupture developed varicella zoster retinitis 2 weeks following injury.

Amblyopia in the traumatised eye was diagnosed in three patients $(4 \%)$, all of whom were $\leq 1$ year of age at the time of injury and one of whom had also developed a mild traumatic cataract.

\section{Visual outcomes}

Final visual acuity data were available for 80 patients (98\%). Sixty-six patients (83\%) achieved a final visual acuity better than 0.30 logMAR (20/40), 10 (12\%) achieved a final visual acuity poorer than $0.30 \log$ MAR but better than $1.00 \log$ MAR $(20 / 200)$, and four $(5 \%)$ had a final visual acuity poorer than $1.00 \log$ MAR.

Table 3 summarises the result of a multivariate logistic regression for risk factors predictive of a final visual acuity of $0.30 \log$ MAR or worse. Age 5 years or younger at the time of injury and associated injuries in zone 3 (ie, posterior segment) were significant predictors of final visual

\begin{tabular}{|c|c|c|}
\hline $\begin{array}{l}\text { Predictor of final VA poorer than } \\
0.30 \text { logMAR }(20 / 40)\end{array}$ & $P$ value & OR $(95 \% \mathrm{Cl})$ \\
\hline Age at injury $\leq 5$ years & $0.017^{\star}$ & 7.73 (1.43 to 41.48$)$ \\
\hline Female sex & 0.614 & 1.54 (0.29 to 8.22$)$ \\
\hline Remote residential area & 0.439 & $2.20(0.30$ to 16.23$)$ \\
\hline Projectile mechanism of injury & 0.918 & $1.09(0.21$ to 5.67$)$ \\
\hline Associated zone 1 injury & 0.423 & $1.81(0.42$ to 7.75$)$ \\
\hline Associated zone 2 injury $\dagger$ & 0.860 & $1.14(0.26$ to 4.97$)$ \\
\hline Associated zone 3 injury & $0.011^{*}$ & 7.60 (1.58 to 36.46$)$ \\
\hline Associated adnexal injury & 0.203 & 2.74 (0.58 to 12.88$)$ \\
\hline
\end{tabular}

${ }^{*} \mathrm{P}<0.05$.

†Excluding hyphaema.

VA, visual acuity; logMAR, logarithm of the minimum angle of resolution.

acuity of less than $0.30 \log$ MAR. Sex, remote residential area, projectile mechanism of injury and associated injuries in zone 1 and zone 2 were not significant predictors of poor visual outcome.

\section{Part 2: Prospective recall examination}

From the original cohort of 82 patients, 59 had sustained their injury $\geq 5$ years prior. From this subset of 59 patients, current contact information was available for $34(58 \%)$, of whom $16(27 \%)$ scheduled and attended a recall examination ( 6 female, 10 male). The mean age at the time of recall examination was 20.6 (range 15-27) years. The mean interval from traumatic hyphaema to recall examination was 9.1 (range 5.6-12.6) years.

\section{Visual function}

The visual acuity in the injured eye and the sound eye did not differ significantly (injured eye mean: -0.05 [range -0.20 to 0.20 ] logMAR; sound eye mean: -0.05 [range -0.20 to 0.10$] \log$ MAR; $\mathrm{t}[15]=0.364, \mathrm{p}=0.721$ ).

Examination of automated perimetry results revealed no glaucomatous visual defects in the recall examination group. The magnitude of the perimetric mean deviation (MD) was significantly greater for the injured eye compared with the sound eye $(-2.75$ [range -5.82 to -0.06 ] dB vs -1.58 [range -4.59 to 0.15 ] dB; $\mathrm{t}[14]=-2.924$, $\mathrm{p}=0.011)$. The perimetric pattern standard deviation (PSD) of the injured eye and sound eye did not differ significantly (2.05 [range 1.37-5.09] dB vs 1.59 [range $1.00-2.43] \mathrm{dB} ; \mathrm{t}[14]=1.601, \mathrm{p}=0.132)$.

\section{Intraocular pressure}

IOP in the injured eye was significantly greater compared with the sound eye (16.7 [range 9-23] mm Hg vs 15.6 [range: 8-22] mm Hg; t[15] $=2.52, \mathrm{p}=0.024)$. The mean IOP asymmetry (injured eye IOP - sound eye IOP) was 1.14 (range -2.0 to 4.0 ) $\mathrm{mm} \mathrm{Hg}$. IOP asymmetry was not significantly correlated with the injured eye visual acuity $\left(R^{2}=0.046, p=0.426\right), M D \quad\left(R^{2}=0.005\right.$, 
$\mathrm{p}=0.807)$, PSD $\left(\mathrm{R}^{2}=0.075, \mathrm{p}=0.323\right)$ or the number of years from injury to recall examination $\left(R^{2}=0.005\right.$, $\mathrm{p}=0.784)$.

\section{Structural outcomes}

Ten patients $(63 \%)$ had angle recession in the injured eye on gonioscopy. One patient had a unilateral cataract attributed to the previous trauma. All patients were judged to have structurally normal optic discs on funduscopy.

Ocular biometry revealed a significantly greater anterior chamber depth (ACD) in the injured eye compared with the sound eye (3.75 [range 3.25-4.12] $\mathrm{mm}$ vs 3.66 [range 3.15-3.93] $\mathrm{mm} ; \mathrm{t}[13]=2.610, \mathrm{p}=0.022)$, but no significant difference in axial length (23.96 [range 22.53-25.69] $\mathrm{mm}$ vs 23.94 [range 22.49-25.78] $\mathrm{mm}$; $\mathrm{t}[13]=0.154, \mathrm{p}=0.880)$. The mean ACD asymmetry (injured eye IOP - sound eye IOP) was 0.09 (range -0.08 to 0.33$) \mathrm{mm}$. Patients with traumatic hyphaema with angle recession had significantly greater ACD asymmetry compared with those with normal angle structures $(0.15$ [range -0.08 to 0.33 ] $\mathrm{mm}$ vs 0.02 [range -0.03 to 0.05 ] $\mathrm{mm} ; \mathrm{t}[7.818]=-2.370, \mathrm{p}=0.046)$.

OCT of the optic disc showed no significant difference in the global average RNFL thickness between the injured and sound eyes (96.6 [range 66-118] $\mu \mathrm{m}$ vs 99.0 [range 81-120] $\mu \mathrm{m} ; \mathrm{t}[15]=1.56, \mathrm{p}=0.140)$. The mean RNFL asymmetry (injured eye - sound eye) was -2.4 (range -16 to 5) $\mu \mathrm{m}$. There was no significant difference in RNFL asymmetry between patients with and those without angle recession ( -2.8 [range -16 to 3 ] $\mu \mathrm{m}$ vs -2.2 [range -15 to 5$] \mu \mathrm{m} ; \mathrm{t}[14]=-0.190, \mathrm{p}=0.852)$ and no significant correlation between RNFL asymmetry and ACD asymmetry $\left(\mathrm{R}^{2}=0.061, \mathrm{p}=0.396\right)$.

A)

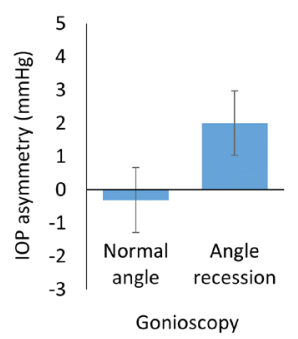

B)

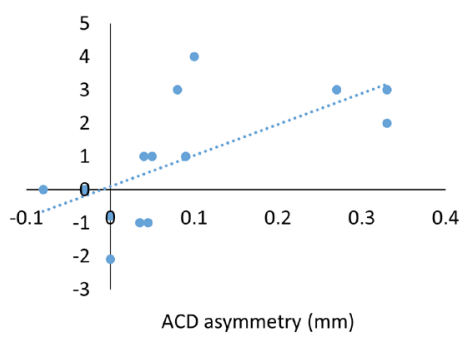

Figure 2 Structural predictors of intraocular pressure (IOP) asymmetry at least 5 years following unilateral traumatic hyphaema. IOP asymmetry was computed as the injured eye IOP minus the sound eye IOP. (A) The relationship between IOP asymmetry and angle recession. Bars represent the mean IOP asymmetry. Error bars represent $95 \% \mathrm{Cl}$. (B) The relation between IOP asymmetry and anterior chamber depth (ACD) asymmetry. ACD asymmetry was computed as the injured eye ACD minus the sound eye ACD. Circles represent individual patient data. The dashed line represents the linear regression line.
Associations between structural outcomes, visual function and IOP As illustrated in figure 2A, patients with traumatic hyphaema with angle recession had significantly greater IOP asymmetry compared with those with normal angle structures (angle recession mean: 2.0 [range -1 to 4] mm Hg; normal angle mean: -0.3 [range -2 to 1$] \mathrm{mm}$ $\mathrm{Hg} ; \mathrm{t}[14]=-3.089, \mathrm{p}=0.008)$. Angle recession was not associated with significant differences in injured eye visual acuity $(-0.04$ [range -0.20 to 0.20 ] $\log$ MAR vs -0.06 [range -0.10 to 0.00 ] $\operatorname{logMAR} ; \mathrm{t}[14]=-0.589$, $\mathrm{p}=-0.566), \mathrm{MD}(-2.66$ [range -5.82 to -0.06 ] $\mathrm{dB}$ vs -2.94 [range -4.64 to -1.99$] \mathrm{dB}$; $\mathrm{t}[13]=-0.347, \mathrm{p}=0.432$ ) or PSD (2.15 [range 1.37-5.09] dB vs 1.84 [1.51-2.12] dB; $\mathrm{t}[13]=-0.553, \mathrm{p}=0.590)$.

Similarly, ACD asymmetry (injured eye - sound eye) showed a significant positive correlation with IOP asymmetry $\left(\mathrm{R}^{2}=0.421, \mathrm{p}=0.012\right)$, such that patients with traumatic hyphaema with greater ACD asymmetry tended to have relatively higher IOPs in their injured eye. A linear regression was computed for the prediction of IOP asymmetry based on the amount of ACD asymmetry, and a significant regression equation was found $(F[1,12]=8.807, \mathrm{p}=0.012)$, with an $\mathrm{R}^{2}$ of 0.423 (figure $2 \mathrm{~B}$ ). The predicted interocular IOP asymmetry in $\mathrm{mm} \mathrm{Hg}$ was equal to $0.106+[9.298 \times(\mathrm{ACD}$ asymmetry, $\mathrm{mm})]$. Therefore, for each additional $0.1 \mathrm{~mm}$ of interocular ACD asymmetry, interocular IOP asymmetry is predicted to increase by approximately $0.9 \mathrm{~mm} \mathrm{Hg}$. ACD asymmetry was not significantly correlated with injured eye visual acuity $\left(\mathrm{R}^{2}=0.113, \mathrm{p}=0.241\right), \mathrm{MD} \quad\left(\mathrm{R}^{2}=0.200, \mathrm{p}=0.126\right)$ or PSD $\left(R^{2}=0.014, p=0.700\right)$.

RNFL asymmetry showed a significant positive correlation with the injured eye MD $\left(R^{2}=0.393, p=0.012\right)$, such that injured eyes with a relatively thinner RNFL had relatively more depressed MD. There was no significant correlation between RNFL asymmetry and injured eye visual acuity $\left(R^{2}=0.092, p=0.252\right)$, PSD $\left(R^{2}=0.013\right.$, $\mathrm{p}=0.688)$ or IOP asymmetry $\left(\mathrm{R}^{2}=0.040, \mathrm{p}=0.455\right)$.

\section{DISCUSSION}

This retrospective and prospective cohort study describes the clinical profile and current practices for paediatric traumatic hyphaema in Western Australia and helps to establish the risk factors for poor visual outcome and long-term complications.

The geographical distribution of the study cohort ( $74 \%$ urban, $13 \%$ regional, $12 \%$ remote) generally reflects the population distribution in Western Australia (71.5\% urban, $21.8 \%$ regional, $6.8 \%$ remote), suggesting that our cohort is broadly representative of the study population. ${ }^{13}$ As Princess Margaret Hospital was the only paediatric hospital in Western Australia at the time, it is unlikely that serious eye injuries requiring hospital admission would have been referred elsewhere.

Consistent with prior studies, the majority of traumatic hyphaemas occurred in males, ${ }^{9-11} 14^{15}$ and the most common place of injury was the home. ${ }^{14} 16$ The prevalence of injury related to sports $(23 \%)$ and caused by 
missiles launched by 'toy' weapons (9\%) was in general agreement with prior reports. ${ }^{9} 10$ However, the prevalence of a projectile mechanism of injury in our study was relatively high $(72 \%)$, possibly reflecting a selection bias towards more severe injury in our study population that excluded patients managed exclusively as outpatients. These findings suggest that public health measures to prevent traumatic hyphaema in children may best be aimed towards safety in the home environment, eye protection in sports and awareness of the potential for eye injury from weapons commonly considered 'toys', such as slingshots and foam pellet guns.

Some of the defining challenges to healthcare in Western Australia are the delivery of care over a vast, sparsely populated area, and the differing needs of remote, regional and urban Australians. ${ }^{17}$ In our study, patients from remote areas experienced a small but significant delay in assessment by an eye specialist, suggesting reduced access to specialist care. Although patients from remote areas also faced longer hospital admissions and shorter duration of follow-up, these differences were likely driven by the challenges of travel and accommodation for patients and families from remote areas rather than injury severity. Despite these differences in time to specialist care and follow-up, residential remoteness was not a significant predictor of final visual outcome.

Acutely elevated IOP and angle recession were common complications in our study cohort. Postinjury IOP elevation $>21 \mathrm{~mm} \mathrm{Hg}$ was noted in approximately $50 \%$ of our study patients, slightly higher than that reported in a similar population, ${ }^{711}$ and IOP typically peaked within 2 weeks of injury. Although several patients required surgery, most surgeries were not directly related to their hyphaema. In line with previously published data, ${ }^{10}$ most hyphaemas resolved with medical management alone, and only a small minority $(1 \%)$ required surgical washout of the anterior chamber. Angle recession represents a tear of the ciliary body at the iris root caused by blunt force trauma. It was observed in approximately half of patients in whom gonioscopy was done. To our knowledge, this is the first study to offer an estimate of the incidence of angle recession following traumatic hyphaema in children. By comparison, the incidence of angle recession following ocular contusion in adults varies from $71 \%$ to $83 \% .^{18} 19$ The reason for this difference is unknown, but may reflect greater elasticity of the iris root and resilience of the ocular tissues to blunt trauma in children. Among the subset of children who suffered injury from a projectile mechanism, however, the incidence of angle recession was significantly greater, and approached that reported for adults.

Closed-globe traumatic hyphaema in children has a favourable visual prognosis. ${ }^{7}$ Although the great majority of patients (83\%) in our study had a final visual acuity of $0.30 \log$ MAR $(20 / 40)$ or better, a minority $(17 \%)$ fared more poorly. Age $<5$ years at the time of injury and associated injury to the posterior segment were independent predictors of poorer final visual acuity. Amblyopia in the injured eye was a limiting factor in final visual acuity for several patients $<5$ years of age, serving as a reminder that clinicians should remain vigilant for secondary amblyopia in young patients with traumatic hyphaema. Among the posterior segment injuries associated with poorer visual outcomes was a case of choroidal rupture followed by varicella zoster retinitis in the immediate postinjury period. Although this sequence of events might be dismissed as incidental, viral retinitis in children has been linked previously with chorioretinal trauma. ${ }^{20}$

The recall examinations conducted between 5 and 12 years postinjury revealed several important insights. Previous cohort studies in adults estimate the incidence of secondary glaucoma following traumatic hyphaema at $5 \%-10 \%$ within 10 years of injury. ${ }^{19}{ }^{21-23}$ If similar rates also apply to children, then we might have expected one or two patients in our study cohort to have developed secondary glaucoma, yet none had. Although perimetric and structural markers of glaucoma were absent, ${ }^{24}$ the recalled patients did exhibit a significant asymmetry in IOP (injured eye IOP $>$ sound eye IOP), which is a known risk factor for glaucoma. ${ }^{25}$ Additionally, Girkin et $a t^{26}$ previously showed that advancing age is an independent risk factor for glaucoma following ocular contusion, so although the patients in our study did not yet have glaucoma their ultimate risk may not be reduced but rather delayed owing to their young age. In this way, although glaucoma was not evident in the recall examination cohort, this finding does not argue against long-term monitoring for post-traumatic glaucoma.

Although visual field testing performed at the recall examination showed no changes indicative of glaucoma, ${ }^{24}$ injured eyes had a small but significant decrement in MD compared with the sound eye. This asymmetry was not apparent in PSD scores, however, suggesting that the MD asymmetry may relate to subtle traumatic optic neuropathy acquired at the time of injury, rather than glaucomatous change.

Perhaps most intriguing, the recall examination revealed significant relationships between ACD asymmetry, IOP asymmetry and angle recession. Indeed, the mean ACD asymmetry in patients with angle recession was $0.13 \mathrm{~mm}$ greater than in patients without angle recession, and a linear regression showed that for each $0.1 \mathrm{~mm}$ increase in ACD asymmetry, IOP asymmetry is predicted to increase by $0.9 \mathrm{~mm} \mathrm{Hg}$. Although limited by a small sample size, our results suggest that ACD asymmetry may be a meaningful surrogate biomarker for angle recession and glaucoma risk. Since ocular biometry is generally well tolerated and non-invasive, it holds promise as a means of assessing structural damage in patients with traumatic hyphaema, such as children, who may be intolerant of gonioscopy.

Contributors MDR conducted data analysis and wrote the manuscript. $\mathrm{KB}$ designed the study, collected data from medical records, performed ophthalmological examinations and reviewed the manuscript. A-MEY contributed to study design, collected data from medical records and reviewed the manuscript. 
KH collected data from medical records. GCL and DAM provided study supervision and reviewed the manuscript.

Funding This study was supported by the Joyce Henderson Bequest Fund for Children's Eye Research, Lions Eye Institute, Perth, Australia.

Competing interests None declared.

Patient consent for publication Not required.

Ethics approval This study was approved by the Princess Margaret Hospital for Children Human Research Ethics Committee (HREC Ref No 2013094EP) and was conducted in accordance with the tenets of the Declaration of Helsinki. Written informed consent was obtained from all patients in the recalled cohort prior to examination.

Provenance and peer review Not commissioned; externally peer reviewed.

Open access This is an open access article distributed in accordance with the Creative Commons Attribution Non Commercial (CC BY-NC 4.0) license, which permits others to distribute, remix, adapt, build upon this work non-commercially, and license their derivative works on different terms, provided the original work is properly cited, appropriate credit is given, any changes made indicated, and the use is non-commercial. See: http://creativecommons.org/licenses/by-nc/4.0/.

\section{REFERENCES}

1. Pizzarello LD. Ocular trauma: time for action. Ophthalmic Epidemiol 1998;5:115-6.

2. Négrel $A D$, Thylefors $B$. The global impact of eye injuries. Ophthalmic Epidemiol 1998;5:143-69.

3. Australian Institute of Health and Welfare. Eye-related injuries in Australia. Canberra: Australian Institute of Health and Welfare, 2009.

4. Yardley AE, Hoskin AK, Hanman K, et al. Paediatric ocular and adnexal injuries requiring hospitalisation in Western Australia. Clin Exp Optom 2017;100:227-33.

5. Agapitos PJ, Noel LP, Clarke WN. Traumatic hyphema in children. Ophthalmology 1987;94:1238-41.

6. Kennedy RH, Brubaker RF. Traumatic hyphema in a defined population. Am J Ophthalmol 1988;106:123-30.

7. Boese EA, Karr DJ, Chiang MF, et al. Visual acuity recovery following traumatic hyphema in a pediatric population. $J$ Aapos 2018;22:115-8.

8. Walton W, Von Hagen S, Grigorian R, et al. Management of traumatic hyphema. Surv Ophthalmol 2002;47:297-334.

9. Recchia FM, Saluja RK, Hammel K, et al. Outpatient management of traumatic microhyphema. Ophthalmology 2002;109:1465-70. discussion 1470-1461.
10. SooHoo JR, Davies BW, Braverman RS, et al. Pediatric traumatic hyphema: a review of 138 consecutive cases. J Aapos 2013;17:565-7

11. Türkcü FM, Yüksel H, Sahin A, et al. Demographic and etiologic characteristics of children with traumatic serious hyphema. Ulus Travma Acil Cerrahi Derg 2013;19:357-62.

12. Pieramici DJ, Sternberg $P$, Aaberg TM, et al. A system for classifying mechanical injuries of the eye (globe). the ocular trauma classification group. Am J Ophthalmol 1997;123:820-31.

13. Australian Bureau of Statistics. Australian Statistical Geography Standard (ASGS). Volume 5 - remoteness structure. Canberra: Australian Bureau of Statistics, 2011.

14. Ashaye AO. Traumatic hyphaema: a report of 472 consecutive cases. BMC Ophthalmol 2008;8.

15. Shiuey Y, Lucarelli MJ. Traumatic hyphema: outcomes of outpatient management. Ophthalmology 1998;105:851-5.

16. Kadappu S, Silveira S, Martin F. Aetiology and outcome of open and closed globe eye injuries in children. Clin Exp Ophthalmol 2013;41:427-34.

17. Wakerman J, Humphreys JS, Wells R, et al. Primary health care delivery models in rural and remote Australia: a systematic review. BMC Health Serv Res 2008;8.

18. Mooney D. Angle recession and secondary glaucoma. $\mathrm{Br} J$ Ophthalmol 1973;57:608-12.

19. Blanton FM. Anterior chamber angle recession and secondary glaucoma. A study of the aftereffects of traumatic HYPHEMAS. Arch Ophthalmol 1964;72:39-43.

20. Tan JCH, Byles D, Stanford MR, et al. Acute retinal necrosis in children caused by herpes simplex virus. Retina 2001;21:344-7.

21. Ng DS, Ching RH, Chan CW. Angle-recession glaucoma: long-term clinical outcomes over a 10-year period in traumatic microhyphema. Int Ophthalmol 2015;35:107-13.

22. Kaufman JH, Tolpin DW. Glaucoma after traumatic angle recession. a ten-year prospective study. Am J Ophthalmol 1974;78:648-54.

23. Bai $\mathrm{HQ}$, Yao L, Wang DB, et al. Causes and treatments of traumatic secondary glaucoma. Eur J Ophthalmol 2009;19:201-6.

24. Canadian Ophthalmological Society Glaucoma Clinical Practice Guideline Expert Committee, Canadian Ophthalmological Society. Canadian Ophthalmological Society evidence-based clinical practice guidelines for the management of glaucoma in the adult eye. Can $J$ Ophthalmol 2009;44(Suppl 1):S7-S54.

25. Williams AL, Gatla S, Leiby BE, et al. The value of intraocular pressure asymmetry in diagnosing glaucoma. J Glaucoma 2013;22:215-8

26. Girkin CA, McGwin G, Long C, et al. Glaucoma after ocular contusion: a cohort study of the United States eye injury registry. $J$ Glaucoma 2005;14:470-3. 